\title{
ESTIMATION OF MOLECULAR AND THERMODIFFUSION COEFFICIENTS FOR NON-IDEAL MOLTEN METAL ALLOYS AND ITS IMPLICATION IN SOLIDIFICATION PROCESS
}

\author{
Elham Jafar-Salehi ${ }^{1}$, Morteza Eslamian ${ }^{2} \dagger$ and M. Ziad Saghir ${ }^{1}{ }^{*}$ \\ 1. Department of Mechanical and Industrial Engineering, Ryerson University, Toronto, Ontario, Canada M5B $2 K 3$ \\ 2. School of Engineering and Computing Sciences, Texas A\&M University-Corpus Christi, TX 78412, U.S.A.
}

In this paper an expression is proposed for the estimation of thermodiffusion factor in liquid metal alloys. The expression can be readily used given that it requires properties that could be easily obtained from the physical properties of the mixture constituents, such as viscosity and molar volume. The predictive power of the proposed expression, as well as other pertinent models is examined against the experimental data. The estimated thermodiffusion factor is then used to study thermo-solutal convection in an enclosure filled with molten Sn-Bi alloy by solving the transport equations numerically. Two simulations were carried out in a vertical rectangular cell encapsulated by a quartz container: top heating and bottom heating. The sidewalls in both cases were exposed to the external natural convection and surface radiation to the ambient. Numerical results show that in the top heating case, the distribution of temperature and concentration are linear, but species segregation occurs due to the thermodiffusion effect. In the bottom heating case, boundary-driven convective flow develops with a large Rayleigh number $(R a)$ where an increase in the $R a$ number negates the thermodiffusion effect due to the development of strong mixing.

Keywords: thermodiffusion, surface radiation, natural convection, solutal convection, molten metal mixture

\section{INTRODUCTION}

$\mathrm{N}$ atural convection in cavities is an interesting and complex heat transfer phenomenon. In natural convection in twodimensional rectangular enclosures, a temperature gradient is usually applied on two opposite walls, that is either topbottom walls or sidewalls. The most widely studied configurations are enclosures heated from below (Rayleigh-Benard convection), and heated from one vertical side and cooled from the other. The temperature gradient may create a boundary-driven flow depending on the configuration.

The fluid flow and heat transfer in the cavity becomes more complex when a binary mixture is used and/or radiation is present in which case the boundaries are no longer insulated. The temperature gradient imposed on a binary mixture causes separation of the species from one another in a phenomenon called thermodiffusion making the problem complex. This will be the focus of this work. In the following sections, the aforementioned phenomena are described and the pertinent research work is reviewed.

Thermodiffusion (thermal diffusion) or Soret effect is mass diffusion due to a temperature gradient in a multi-component liquid (and also gas and even solid) mixture. The most common driving force for mass diffusion is the presence of a spatial concentration or chemical potential difference within a solution or mixture. In a homogeneous solution, temperature or pressure gradients may also cause mass diffusion. Normally the thermodiffusion factor $\alpha$, Soret coefficient $S_{T}$ and the thermodiffusion coefficient $D_{\mathrm{T}}$ are related to each other and to the molar flux of component $1\left(J_{1}\right)$ through the modified Fick's law, written as follows:

$$
\begin{aligned}
J_{1} & =-c D\left[\nabla c_{1}+\frac{\alpha_{\mathrm{T}} c_{1} c_{2}}{T} \nabla T\right]=-c D\left[\nabla c_{1}+S_{T} c_{1} c_{2} \nabla T\right] \\
& =-c\left[D \nabla c_{1}+D_{T} c_{1} c_{2} \nabla T\right]
\end{aligned}
$$

where $c$ is the mixture molar density, $D$ is the inter-diffusion or molecular diffusion coefficient, $c_{1}$ and $c_{2}$ are the mass fractions of components 1 and $2, \nabla c_{1}$ is the spatial gradient of component 1 and $\nabla T$ is the spatial temperature gradient. Equation (1) is usually used in one-dimension as most experiments are designed such that the heat and mass transfer occur in one direction only. Thermodiffusion is utilised for species separation in liquid molten metal alloys, ${ }^{[1,2]}$ separation of polymer blends, ${ }^{[3]}$ particle and macromolecule manipulation, ${ }^{[4]}$ and for the composition estimation in underground hydrocarbon reservoirs in a porous medium, ${ }^{[5]}$ to name a few. A recent review of advances and applications is given in Ref. ${ }^{[6]}$

Among several theoretical approaches proposed in thermodiffusion, the present authors have followed the linear non-equilibrium thermodynamics (LNET) approach due to its simplicity at least for simple mixtures that have minimal structural complexity such as hydrocarbon mixtures. In the LNET approach, heat and mass (molar) fluxes are correlated linearly with the thermodynamic forces, such as temperature and concentration gradients. In the presence of a temperature gradient across a mixture, the molar diffusion flux of the $i$ th component may be written as follows, assuming that pressure gradient is 0 both locally and globally ${ }^{[7]}$ :

\footnotetext{
$\dagger$ Morteza Eslamian's present address is University of Michigan-Shanghai Jiao Tong University Joint Institute, Minhang District, Shanghai, China *Author to whom correspondence may be addressed. E-mail address: zsaghir@ryerson.ca

Can. J. Chem. Eng. 92:1314-1324, 2014

(C) 2014 Canadian Society for Chemical Engineering DOI 10.1002/cjce.21972

Published online 7 February 2014 in Wiley Online Library (wileyonlinelibrary.com).
} 
$J_{i}=\sum_{k=1}^{n} L_{i k}\left[Q_{k}^{*} \frac{\nabla T}{T}+\sum_{j=1}^{n-1} \frac{\partial \mu_{k}}{\partial c_{j}} \nabla c_{j}\right]$

where $L_{i k}$ are the phenomenological coefficients, $\mu_{k}$ is the chemical potential and $Q_{k}^{*}$ is the net heat of transport of component $k$, which is the heat flow per mole of the diffusing component $k$, required to be absorbed during mass diffusion by the local region to keep the temperature constant. While the temperature gradient and heat flow are present, the mass fluxes vanish when a steady but nonuniform concentration profile has developed within the mixture. For thermodiffusion as a coupled heat and mass transfer phenomenon, the phenomenological coefficients $L_{i k}$ are nonzero, and the sum of all terms in the square brackets in Equation (2) is $0 .{ }^{[8,9]}$ This equation relating $\nabla T$ and $\nabla c_{j}$ combined with Equation (1) and the Gibbs-Duhem relationship, at constant pressure and temperature results in the thermodiffusion factor $\left(\alpha_{\mathrm{T}}\right)$ of the first component in terms of the net heat of transport:

$\alpha_{\mathrm{T}}=\frac{Q_{1}^{*}-Q_{2}^{*}}{c_{1}\left(\partial \mu_{1} / \partial c_{1}\right)}$

In steady state, all velocities and fluxes are 0 , regardless of the velocity frame of reference $\left(J_{1}=0 ; J_{2}=0\right)$. We also note that Equation (3) is valid for any velocity frame of reference. ${ }^{\left[{ }^{9]}\right.}$ If $\alpha_{\mathrm{T}}$ is positive, the first component is enriched on the cold side. Following the works of Drickamer and coworkers, ${ }^{[10]}$ Eslamian and Saghir ${ }^{[11]}$ replaced the net heat of transport in Equation (3) with the Eyring's activation energy of viscous flow in pure state $\left(E^{\mathrm{vis}}\right)$. Despite very complex nature of the heat of transport, it was found that the model is systematically and qualitatively valid for liquid mixtures made of non-associating molecules. This proposed modified equation is written as follows:

$\alpha_{\mathrm{T}}=\frac{E_{1}^{\mathrm{vis}}-E_{2}^{\mathrm{vis}}}{c_{1}\left(\partial \mu_{1} / \partial c_{1}\right)}$

To obtain the Eyring's activation energy of viscous flow, an Arrhinus dependence of viscosity to temperature and activation energy is assumed. When the (kinematic) viscosity is plotted against $1 / R T, R$ being the gas constant, a line is obtained whose slope is the activation energy of viscous flow of that liquid component. ${ }^{[12]}$ This is the energy per mole of liquid that is needed to trigger liquid motion.

The most relevant research work to the present work is the study of thermodiffusion and convection in a binary mixture of molten semiconductor-metal mixtures, for example silicon as a semiconductor and aluminium, gallium and gold as metal dopants. $^{[13]}$

There are numerous works on natural convection in cavities. Here pertinent natural convection works that include radiation or binary mixtures are reviewed. Nogueira et al. ${ }^{[14]}$ studied the effect of the aspect ratio and Rayleigh number on heat transfer in a cavity. It was found that the Rayleigh number greatly influences the heat transfer and flow profile inside the cavity. Basak et al. ${ }^{[15-17]}$ studied the convection flow in a square cavity of linearly heated sidewalls as a function of increasing $\operatorname{Pr}$ number. It was found that the number of circulation cells in the cavity increases as the $\operatorname{Pr}$ number increases.

Ouriemi et al. ${ }^{[18]}$ studied the convection in a horizontal shallow cavity of a binary fluid considering both the double diffusive and Soret-induced convection. Using numerical and analytical method, they predicted the critical Rayleigh number at the onset of supercritical and sub-critical convection. In another study, Paroncini and Corvaro ${ }^{[19]}$ studied the effect of source height on the convective heat transfer and determined that the heat transfer decreases as the source height increases.

Natural convection may be also present in some of the crystallisation processes, ${ }^{[20-27]}$ which is the subject of our other work to be published separately. In solidification of binary molten alloys, all phenomena involved in heat transfer of a binary alloy without solidification is present as well as the solidification process, which is the last stage.

Natural convection in cavities may be affected by radiation exchange between the surfaces and also from the surfaces to the surrounding. This may alter the flow patterns and heat transfer characteristics. The interaction of natural convection with thermal radiation induced in a square cavity filled with air and differentially heated was studied numerically by Balaji and Venkateshan $^{[28,29]}$ and by Akiyama and Chong. ${ }^{[30]}$ Ramesh et al. ${ }^{[31,32]}$ conducted numerical and experimental studies in a square cavity with differentially heated, isothermal vertical walls. Ridouane et al. ${ }^{[33]}$ analysed numerically the coupling between natural convection and surface radiation in a square cavity heated from below. It was concluded that the surface radiation considerably reduces the critical Rayleigh numbers characterising the transition from steady toward oscillatory convection. Gururaja Rao et al. ${ }^{[34]}$ studied numerically the problem of multimode heat transfer from a square-shaped electronic device provided with three identical discrete heating sources. Relative contributions of convection and surface radiation to heat dissipation from the device were also quantified. Bahlaoui et al. ${ }^{[35]}$ studied numerically the coupling between natural convection and radiation in a tall rectangular cavity. The results showed the existence of multiple steady-state solutions in an inclined cavity and that the number of the obtained solutions was affected by the presence of radiation. It was reported that the increase of the emissivity leads to a reduction of the number of solutions for weak values of the Rayleigh number, while the increase of the latter favours the multiplicity of solutions for all the values of emissivity considered. Han and Baek $^{[36]}$ studied the coupling between radiation and natural convection in a rectangular enclosure with two incomplete partitions under a large temperature difference. Results of this study showed that the radiation alters the fluid dynamic and temperature distribution compared with cases without surface and gas radiation, where the effect of the latter was found to be more important than that of the former. Balaji and Venkateshan, ${ }^{[37,38]}$ Hinojosa et al. ${ }^{[39]}$ and Dehghan and Behnia $^{[40]}$ studied the coupling between convection and surface radiation in partially opened cavities either uniformly or discretely heated. Their results showed that the radiation affects the dynamical and thermal structures of the fluid, reduces the natural convective heat transfer component, and contributes to an increase in the total amount of heat exchanged in the configurations considered.

In the above studies, the thermal boundary conditions were assumed to be either steady and isothermal or constant heat flux. However, in many engineering applications, the energy provided to the system is variable in time and gives rise to unsteady natural-convection flows. Solar collectors and printed circuit boards are examples of such systems submitted to variable thermal boundary conditions. In addition, thermal and dynamical behaviours of a fluid subjected to time-dependent thermal conditions are impossible to predict on the basis of the results obtained with constant temperature or heat flux conditions. 
Therefore, several researchers have studied the problem of unsteady boundary condition, for example. ${ }^{[41-48]}$ In the present work, we have assumed steady boundary conditions on the top and bottom walls and unsteady boundary conditions on the sidewalls. On the sidewalls, the ambient temperature is assumed constant, and the presence of radiation and natural convection from the outer walls result in an unsteady boundary condition on the sidewalls. In an earlier study, Lage and Bejan ${ }^{[41]}$ studied numerically and theoretically the problem of natural convection in enclosures with one side heated with a pulsating heat flux. They showed that the buoyancy-induced flow resonates to a certain frequency of the pulsating heat input and the resonance phenomenon is characterised by maximum fluctuations observed in the heat transfer evolution with the period of the time-dependent temperature. In the case of a square cavity totally or partially heated from below with periodic variable temperatures, it was shown that the resulting flow structure and heat transfer are strongly dependent on the amplitude and the period of the variable temperature. ${ }^{[42]}$ Transient natural convection in a square cavity isothermally cooled from above and partially heated from the side was also studied. ${ }^{[43]}$ Antohe and Lage ${ }^{[44,45]}$ investigated the transport of momentum and heat while considering clear fluid and fully saturated porous medium differentially heated enclosures with a time-periodic pulsating heat flux. It was found that the naturalconvection activity within the enclosure reaches several local maxima for certain values of the heating frequency. Kwak et al. ${ }^{[46,47]}$ also studied such a resonant phenomenon of natural convection.

In light of the above literature review and based on a practical need (for the experimental study of thermodiffusion in binary fluids in a cuboid glass cell using optical methods), the external natural convection coupled with surface radiation to the ambient in a rectangular quartz cavity filled with binary molten metal alloys is studied here, where the thermodiffusion effect and internal natural convection are also present. The focus and novelty of the present work is first to propose an expression to estimate thermodiffusion factor in a wide range of molten metal alloys and then to simulate the natural convection with external radiation and convection and thermodiffusion in a $2 \mathrm{D}$ rectangular quartz cavity filled with $\mathrm{Sn}-\mathrm{Bi}$ mixture. There is essentially no other work that considers thermodiffusion in convective flow of molten alloys. The rest of this paper is structured as follows: section "The Estimation of Thermodiffusion Factor" outlines the modification of Eslamian et al. ${ }^{[1]}$ and Maier et al. ${ }^{[49]}$ expressions to account for the chemical potential effect in the calculation of thermodiffusion factor. Section "Numerical Modelling of Natural Convection" outlines the numerical simulation of natural convection in a cavity including the surface to ambient radiation and thermodiffusion effects. In fourth section presents the results and discussion and in fifth section major conclusions are drawn.

\section{THE ESTIMATION OF THERMODIFFUSION FACTOR}

The origin of thermodiffusion forces in liquid metal mixtures are believed to be due to ion-ion interactions and electron-ion interactions. ${ }^{[50]}$ The electron-ion forces exist as a result of the interaction between free electrons in the mixture and the ions of like and unlike components in a binary mixture that contains free electrons such as molten metal alloys. Eslamian et al. ${ }^{[1]}$ defined a new heat of transport $q_{k}^{*}$ for the electron-ion forces, and applied the non-equilibrium thermodynamics formulation on molten metal mixtures:
$\alpha_{\mathrm{T}}=\frac{Q_{1}^{*}-Q_{2}^{*}}{c_{1}\left(\partial \mu_{1} / \partial c_{1}\right)}+\frac{q_{1}^{*}-q_{2}^{*}}{c_{1}\left(\partial \mu_{1} / \partial c_{1}\right)}$

It has been shown that electronic net heat of transport of constituent 1 with respect to constituent 2 may be obtained as follows ${ }^{[1]}$ :

$q_{1}^{*}-q_{2}^{*}=-|e|\left(z S_{1}-z_{1} S\right) T N$

where $|e|$ is the absolute value of the electron charge, $z_{i}$ is the valence of the ion $i, z$ is the mean valence of the ions in the mixture and $S_{i}$ is the thermoelectric power of the ions of type $i$. A linear mixing rule is the simplest approximation to obtain the mixture thermoelectric power $S$. The following equation was used to approximate the thermoelectric power of a pure liquid metal ${ }^{[1]}$ :

$S_{i}=-\frac{\pi^{2} k_{\mathrm{B}}^{2} T}{3|e| E_{\mathrm{f}}} \xi_{i}$

where $\xi$ is a dimensionless parameter and somewhat independent of temperature, $k_{\mathrm{B}}$ is the Boltzman constant and $E_{\mathrm{f}}$ is the Fermi energy. ${ }^{[1]}$

On the other hand, Maier et al. ${ }^{[49]}$ followed also the nonequilibrium thermodynamics approach as outlined by Faber ${ }^{[51]}$ and obtained the following expression for the thermodiffusion factor in a dilute solution:

$\alpha_{\mathrm{T}}=\frac{1}{2} \frac{Q_{1}^{*}-h_{1}+h_{2}}{c_{1}\left(\partial \mu_{1} / \partial c_{1}\right)}$

where $h_{1}$ and $h_{2}$ are the partial specific enthalpies of components 1 and 2 , and $c_{1}$ is the mass fraction of component 1 . Equation (8) is similar to Equation (3), although the numerator is different because of different interpretation of the heat of transport adopted by Faber ${ }^{[51]}$ and Maier et al. ${ }^{[49,51]}$ who argued that $Q_{1}^{*}$ is the difference between the latent heat of fusion of component 1 in the mean molar volume of the mixture and the latent heat of fusion of the pure component 1 , expressed as follows:

$Q_{1}^{*}=\frac{L_{\mathrm{f}}}{m_{1}}\left(\frac{\frac{1}{2}\left(V_{1}+V_{2}\right)}{V_{1}}-1\right)$

where $m_{1}$ is the molar mass of constituent $1, V_{1}$ and $V_{2}$ are the molar volumes of components 1 and 2 , and $L_{\mathrm{f}}$ is the latent heat of fusion. They obtained the derivative of the chemical potential of component 1 with respect to $c_{1}$ for dilute mixtures as follows:

$$
\frac{\partial \mu_{1}}{\partial c_{1}}=\frac{R T V_{2} m_{1}}{c_{1}\left(c_{1} V_{1} m_{2}+V_{2} m_{1}-V_{2} m_{1} c_{1}\right)}
$$

Therefore, by combining Equations (8) and (10), one arrives at the thermodiffusion factor as follows:

$\alpha_{\mathrm{T}}=\frac{1}{2} \times \frac{\left(\Delta S_{\mathrm{ls}}(T) T \frac{V_{\mathrm{mmol}}-V_{\text {moll }}}{V_{\text {moll }}}-h_{1}+h_{2}\right)\left(c_{1} V_{1} m_{2}+V_{2} m_{1}-V_{2} m_{1} c_{1}\right)}{R T V_{2} m_{1}}$

where $S_{\text {ls }}(T)$ is the partial specific entropy difference between the solid and liquid state of components at temperature $T$. Even though not taking into account the electronic contribution, predictions of Equation (11) showed a good agreement with some experimental data. $^{[52]}$ 
Based on forgoing discussion, we formulate a practical expression for the thermodiffusion factor of the first component in a liquid metal alloy by introducing the new chemical potential given by Equation (10) in the denominator of Equation (5):

$\alpha_{\mathrm{T}}=\frac{E_{1}^{\mathrm{vis}}-E_{2}^{\mathrm{vis}}}{\left(\frac{R T V_{2} m_{1}}{c_{1}\left(c_{1} V_{1} m_{2}+V_{2} m_{1}-V_{2} m_{1} c_{1}\right)}\right)}+\frac{-|e|\left(z S_{1}-z_{1} S\right) T N}{\left(\frac{R T V_{2} m_{1}}{c_{1}\left(c_{1} V_{1} m_{2}+V_{2} m_{1}-V_{2} m_{1} c_{1}\right)}\right)}$

Equation (12) has two terms on the right hand side that may have the same or opposite signs depending on metal alloy characteristics. For the purpose of comparison, the results of the proposed expression were compared with that of Eslamian et al. ${ }^{[1]}$ as well as some experimental data. ${ }^{[52,53]}$ It is shown that the proposed thermodiffusion factor agrees well with the experimental results (Results section).

\section{NUMERICAL MODELLING OF NATURAL CONVECTION}

Two numerical simulations were carried out on natural convection of a binary molten metal alloy of $\mathrm{Sn}$-Bi mixture enclosed in a cavity incorporating the thermodiffusion effect and heat loss by surface radiation to ambient combined with external natural convection. The flow was assumed to be laminar and incompressible. In this simulation, a constant heat source was considered to model the temperature difference on the opposing boundaries. Two configurations, top heating and bottom heating in a rectangular cavity encapsulated with quartz walls were studied. Heat losses by natural convection and surface radiation from the vertical walls to the surrounding are taken into consideration. Material properties for the given model are given in Table 1 .

The complete nonlinear Navier-Stokes equations for laminar, incompressible Newtonian flows in the steady state condition together with the energy and mass equations were solved numerically using the finite element technique. ${ }^{[54]}$

\section{Governing Equations and Boundary Conditions}

The continuity, concentration, momentum and energy balance equations are solved in order to study the flow, concentration and heat transfer characteristics of the problem. The governing

Table 1. The physical properties of $\mathrm{Sn}-\mathrm{Bi}$ mixture at $295^{\circ} \mathrm{C}\left({ }^{[1]}\right.$ and the references therein)

\begin{tabular}{lcc}
\hline Physical properties & Symbols & $\mathrm{Sn}-\mathrm{Bi}$ \\
\hline Initial concentration for $\mathrm{Sn}$ & $C_{i}$ & 0.05 \\
Dynamic viscosity & $\eta$ & $16 \times 10^{-3} \mathrm{~g} \mathrm{~cm}^{-1} \mathrm{~s}^{-1}$ \\
Density & $\rho$ & $8.325 \mathrm{~g} \mathrm{~cm}^{-3}$ \\
Hot temp & $T_{\mathrm{H}}$ & $307^{\circ} \mathrm{C}$ \\
Cold temp & $T_{\mathrm{C}}$ & $283^{\circ} \mathrm{C}$ \\
Conductivity & $K$ & $0.381 \mathrm{~J} \mathrm{~s}^{-1} \mathrm{~cm}^{-1} \mathrm{k}^{-1}$ \\
Specific heat capacity & $C_{p}$ & $0.1745 \mathrm{Jg}^{-1} \mathrm{k}^{-1}$ \\
Prandtl number & $P r$ & $7.33 \times 10^{-3}$ \\
Solutal expansion & $\beta C$ & $48.02 \times 10^{-4}$ \\
Thermal volume expansion & $\beta_{\mathrm{T}}$ & $1.01 \times 10^{-4}\left(\mathrm{~K}^{-1}\right)$ \\
Kinematic viscosity & $V$ & $1.922 \times 10 \mathrm{~cm}^{-2} \mathrm{~s}^{-1}$ \\
Thermal diffusivity & $\alpha$ & $0.2622 \mathrm{~cm}^{2} \mathrm{~s}^{-1}$ \\
Characteristic velocity & $u_{\mathrm{o}}$ & $0.2622 \mathrm{~cm} \mathrm{~s}^{-1}$ \\
Reynolds number & $R e$ & 136 \\
Soret coefficient & $S_{T}$ & $0.248\left(\mathrm{~K}^{-1}\right)$ \\
Schmidt number & $S c$ & 101.566 \\
Thermodiffusion factor & $\alpha_{\mathrm{T}}$ & 0.141 \\
\hline
\end{tabular}

equations are rendered dimensionless by using the following non-dimensional variables ${ }^{[12]}$ :

$$
\begin{array}{cccc}
U=\frac{u}{u_{\mathrm{o}}} & V=\frac{v}{u_{\mathrm{o}}} & X=\frac{x}{L} & Y=\frac{y}{L} \quad P=\frac{p L}{\eta u_{\mathrm{o}}} \\
\theta=\frac{T-T_{\mathrm{c}}}{\Delta T} & C=\frac{c-c_{\mathrm{o}}}{\Delta c} & \Delta T=T_{\mathrm{H}}-T_{\mathrm{c}} & u_{\mathrm{o}}=\sqrt{g \beta_{\mathrm{T}} \Delta T L}
\end{array}
$$

where $U$ and $V$ are dimensionless velocity, $P$ is dimensionless hydrodynamic pressure, $\theta$ is non-dimensional temperature, $C$ is the non-dimensional concentration of a mixture component, $g$ is the gravitational acceleration, $u_{0}$ is a reference velocity, $\Delta T$ the initial temperature difference and $L$ is a characteristic length.

\section{Continuity equation}

$$
\frac{\partial U}{\partial X}+\frac{\partial V}{\partial Y}=0
$$

\section{Concentration equation}

$$
\operatorname{Re}\left[U \frac{\partial C}{\partial Y}+V \frac{\partial C}{\partial Y}\right]=\frac{1}{S c}\left\{\left[\frac{\partial^{2} C}{\partial X^{2}}+\frac{\partial^{2} C}{\partial Y^{2}}\right]+\alpha_{T}\left[\frac{\partial^{2} \theta}{\partial X^{2}}+\frac{\partial^{2} \theta}{\partial Y^{2}}\right]\right\}
$$

\section{Momentum equation \\ $X$-direction}

$\operatorname{Re}\left[U \frac{\partial U}{\partial X}+V \frac{\partial V}{\partial Y}\right]=\frac{\partial P}{\partial X}+\left[\frac{\partial^{2} U}{\partial X^{2}}+\frac{\partial^{2} U}{\partial Y^{2}}\right]$

\section{Y-direction}

$\operatorname{Re}\left[U \frac{\partial U}{\partial X}+V \frac{\partial V}{\partial Y}\right]=\frac{\partial P}{\partial X}+\left[\frac{\partial^{2} V}{\partial X^{2}}+\frac{\partial^{2} V}{\partial Y^{2}}\right]-\operatorname{Re}[\theta-N C]$

\section{Energy equation}

$\operatorname{Re} \cdot \operatorname{Pr}\left[U \frac{\partial \theta}{\partial X}+V \frac{\partial \theta}{\partial Y}\right]=\left[\frac{\partial^{2} \theta}{\partial X^{2}}+\frac{\partial^{2} \theta}{\partial Y^{2}}\right]$

where in above equations $S c=\mu / \rho D$ is the Schmidt number, $\alpha_{\mathrm{T}}=T D_{\mathrm{T}} / D$ is the thermodiffusion factor, $\operatorname{Re}=\left(\rho_{\mathrm{o}} u_{\mathrm{o}} L\right) / \mu$ is the Reynolds number and $\operatorname{Pr}=v / \alpha$ is the Prandtl number. The aim of this work is to study the distribution of temperature and concentration due to the presence of thermodiffusion using the proposed thermodiffusion factor as one of the variables within the cavity of $\mathrm{Sn-Bi}$ molten binary mixture metal and in the presence of surface radiation to ambient and external natural convection. Equations (14)-(18) were solved numerically using the finite element technique.

\section{Model Geometry and Boundary Conditions}

Figure 1 shows the geometry of the rectangular cavity filled with the binary molten metal. The cell is $10 \mathrm{~mm}$ in the vertical direction with two quartz plates of $1 \mathrm{~mm}$ thick, one at the bottom and one on the top. The width of the model cell is $3 \mathrm{~mm}$ in the horizontal direction with two quartz plates of $1 \mathrm{~mm}$ thick on each side. The thermal boundary conditions here dictate heat losses to the surrounding through radiation and external natural convection from the vertical walls. As mentioned earlier, two cell configurations were considered here, top heating and bottom heating. A 


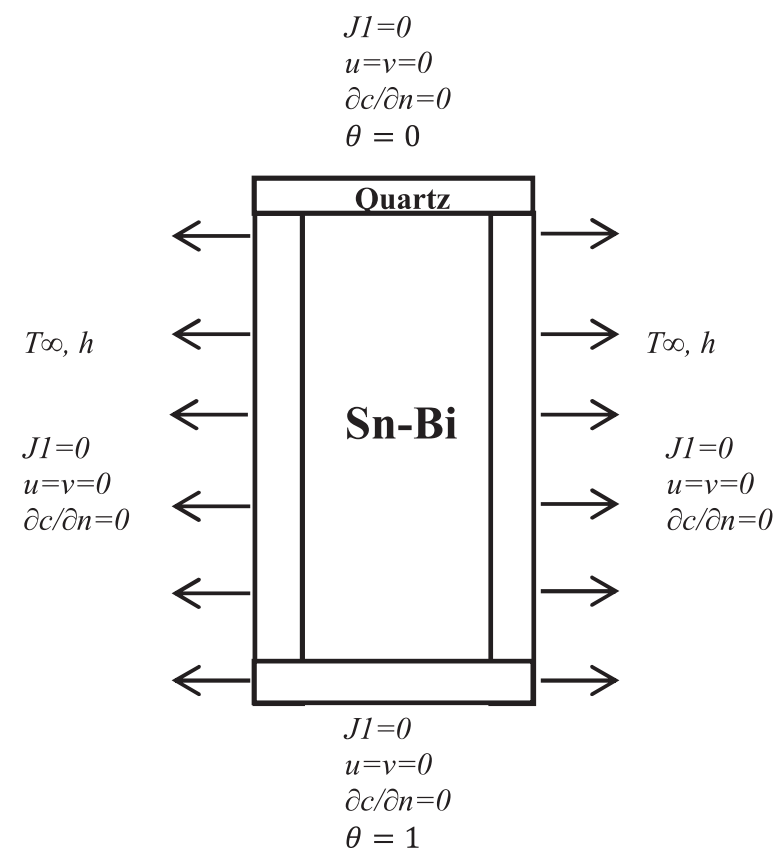

Figure 1. Computational cell geometry and boundary conditions.

constant heat source was applied to the top surface and the hot and cold surfaces were reversed in the second simulation. Furthermore, the velocity and the mass flux $\left(J_{i}\right)$ at all external walls of the cavity were assumed 0 , given that this is a boundarydriven flow problem.

\section{Mesh Sensitivity Analysis}

In general, the final results of the numerical simulations could be sensitive to the mesh size. A series of simulations with identical boundary conditions were performed to study the mesh sensitivity and to determine the optimal mesh size. In addition, the mesh at the boundary was further refined to achieve a greater accuracy of temperature and velocities variation at the boundaries. As the first step, a model with a coarse mesh was used to simulate the fluid behaviour. In order to check the mesh independency, the mesh was refined. The process of refining was stopped as the simulation results from the previous simulation to the current simulation did not change by more than few percent. This procedure ensured that the numerical results were not sensitive to the mesh size and the results were consistent.

\section{RESULTS AND DISCUSSION}

\section{Estimation of the Thermodiffusion Factors}

Mathematical models are usually validated if their prediction agrees with reliable experimental data. There are many issues influencing the experimental data and in turn the validity of numerical models. Gravity is one of the parameters that may affect the accuracy of thermodiffusion data via triggering convective flows, particularly in mixtures such as molten metal alloys.

Thermodiffusion coefficient factors in selected mixtures estimated by our proposed equation are listed in Table 2 . The experimental values and predictions of Eslamian et al. ${ }^{[1]}$ are given in Table 2, as well. Our proposed formula, Equation (12) predicts the experimental data better than that of Eslamian et al. ${ }^{[1]}$ The percentage of relative errors are shown in parentheses as well. It is a relative error
Table 2. Comparison of calculated thermodiffusion factor $\left(\alpha \times 10^{3}\right)$ against the experimental data

\begin{tabular}{lccccc}
\hline Mix. & $T_{\text {ave }}(K)$ & $x_{1}$ & Expt. & Eslamian & This work \\
\hline $\mathrm{Sn}-\mathrm{Bi}$ & 568 & 0.50 & -100 & $-396(296)$ & $-141(41)$ \\
$\mathrm{Sn}-\mathrm{Cd}$ & 568 & 0.50 & -350 & $-263(-25)$ & $-398(13)$ \\
$\mathrm{Sn}-\mathrm{Zn}$ & 648 & 0.50 & -4100 & $-3085(-25)$ & $-4099(-0.02)$ \\
$\mathrm{Sn}-\mathrm{Pb}$ & 568 & 0.50 & -1900 & $-1143(-40)$ & $-1753(-7.7)$ \\
$\mathrm{Sn}-\mathrm{Pb}$ & 723 & 0.50 & -830 & $-685(-17)$ & $-946(13.9)$ \\
$\mathrm{Sn}-\mathrm{Ga}$ & 568 & 0.50 & -180 & $374(-307)$ & $99(-155)$ \\
$\mathrm{Bi}-\mathrm{Pb}$ & 568 & 0.50 & -1130 & $-72(-94)$ & $-260(-76)$ \\
\hline \multicolumn{5}{l}{ Errors are given in brackets. } \\
\hline
\end{tabular}

between the experimental data (assuming that there is no error associated with it) and the calculated values for the thermodiffusion factor based on a theoretical model expression can be defined as follows:

Error $=\frac{\alpha_{\text {Theory }}-\alpha_{\text {Expt }}}{\alpha_{\text {Expt }}} \times 100$

Both Equation (12) and Eslamian et al.'s expressions fail to predict the sign of thermodiffusion factor in Sn-Ga mixture. Nevertheless, Equation (12) shows a better prediction power. Note that the Maier's expression, Equation (11) does not account for the electronic forces, and therefore it is incomplete when used for metal containing mixtures. In addition, Figure 2 depicts the predictive trend of variation of thermodiffusion factor versus mole fraction, for various molten metal mixtures at a given temperature obtained by the proposed model and also by the Haase, ${ }^{[55]}$ Kempers, ${ }^{[56]}$ Shukla and Firoozabadi, ${ }^{[57]}$ Winter and Drickamer $^{[10]}$ and Eslamian et al. ${ }^{[1]}$ models. We note that for each mixture there is only one experimental data point for a given concentration.

Figure 3 shows the thermodiffusion coefficient of the first component of $\mathrm{Sn}-\mathrm{Bi}, \mathrm{Sn}-\mathrm{Pb}, \mathrm{Bi}-\mathrm{Pb}, \mathrm{Sn}-\mathrm{Ga}$ and $\mathrm{Na}-\mathrm{K}$ mixtures versus temperature. To calculate the thermodiffusion coefficient from the thermodiffusion factor, molecular diffusion coefficient, $D$, should be obtained a priori. As an approximation, we employ the Einstein-Stokes relation to estimate the thermodiffusion coefficient of spherical molecules in a liquid of given viscosity. One mathematical model that has shown very promising results was proposed by Maier et al., Equation (11). However, their model does not take into account the electron-electron interaction forces. In this work for the purpose of comparison, authors have added this effect to the Maier model and compared the results with the experimental data. The results are listed in Table 3. The theoretical estimations of the modified model are not necessarily better than the original model, due to other uncertainties and approximations in the original model.

\section{Top and Bottom Heating Natural Convection}

The transport equations combined with the Soret effect were solved in a rectangular quartz cell containing molten $\mathrm{Sn}-\mathrm{Bi}$ mixture. Dimensionless solutions for the flow with different Raleigh numbers for the two top and bottom heating cases with thermodiffusion, surface radiation and external natural convection effect are shown in Figures 4-7. The main purpose of this study is to investigate the effect of thermodiffusion, surface radiation and external natural convection on heat transfer through the molten Sn-Bi mixture. 

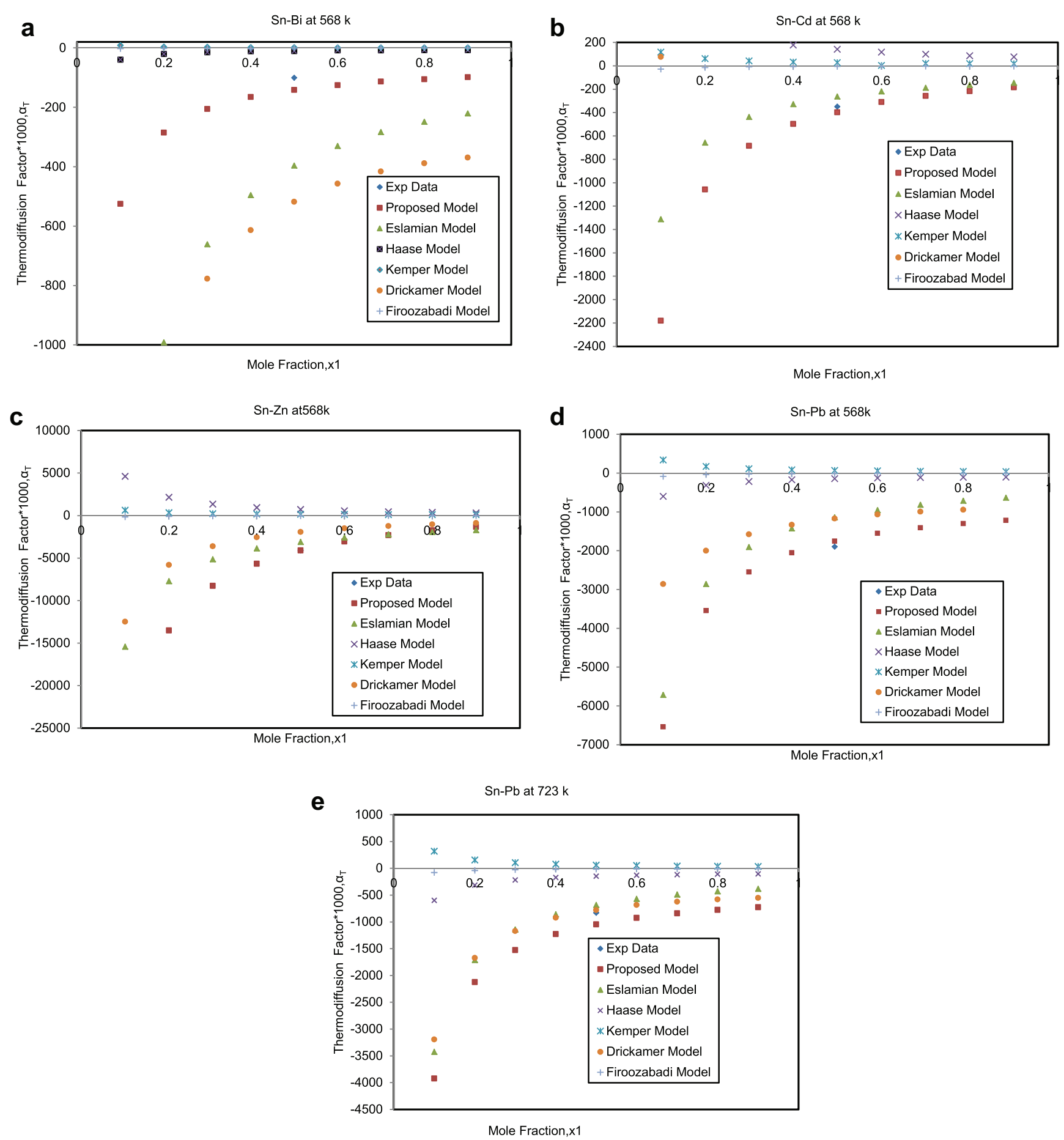

Figure 2. Effect of concentration on thermodiffusion factor: comparison of the prediction of different models. Note that the experimental data is only available for an equimolar mixture. (a) Sn-Bi at $568 \mathrm{~K}$, (b) Sn-Cd at $568 \mathrm{~K}$, (c) Sn-Zn at $568 \mathrm{~K}$, (d) Sn-Pb at $568 \mathrm{~K}$ and (e) Sn-Pb at $723 \mathrm{~K}$.

\section{Case 1: Top heating condition}

Figure 4 shows temperature and concentration distribution along the rectangular cavity when the heating was from the top surface. Consequently, the bottom surface was considered to be the cold surface. Simulation results revealed that the system is in a pure diffusive regime. Thermodiffusion effects showed separation of the solute in the molten metal alloy. Heat losses to the environment proved not to have any major effect on the separation process.
Figure 4a shows the contour plot of the temperature distribution. In Figure $4 b$, the horizontal axis is the distance along the vertical direction and the vertical axis is the temperature distribution. The temperature decreases linearly from the top surface to the bottom surface. As the graph indicates, the temperature gradient is constant along the vertical walls since it is a pure diffusive regime. Figure 4c depicts the contour plot of the concentration of Sn and Figure $4 \mathrm{~d}$ depicts the concentration of Sn distribution. In this simulation, the initial concentration of $\mathrm{Sn}$ was set at 0.05 . In the top 


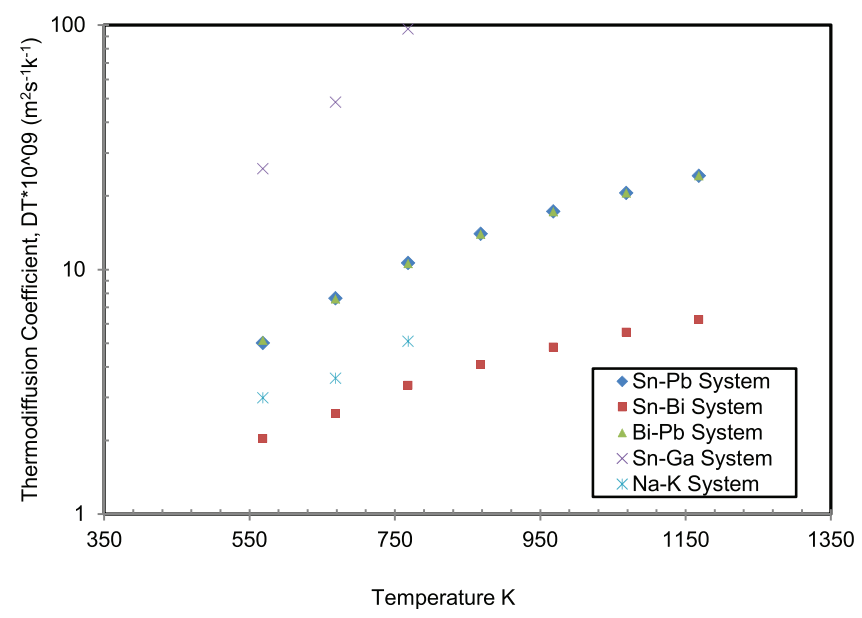

Figure 3. Thermodiffusion coefficient of binary molten metals at various temperatures and $x_{1}=0.5$ by using Stokes-Einstein equation for each component and the proposed model for: $\mathrm{Sn}-\mathrm{Bi}, \mathrm{Sn}-\mathrm{Pb}, \mathrm{Sn}-\mathrm{Ga}, \mathrm{Bi}-\mathrm{Pb}$ and $\mathrm{Na}-\mathrm{K}$.

a

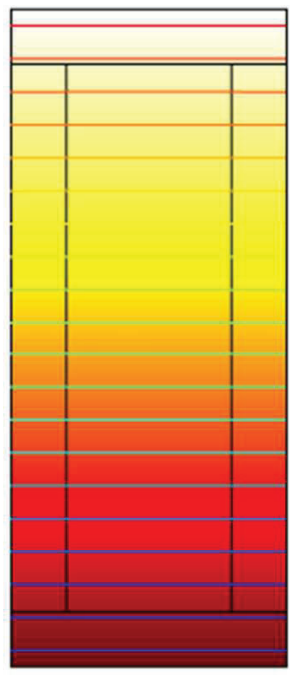

$\Delta 0.975$

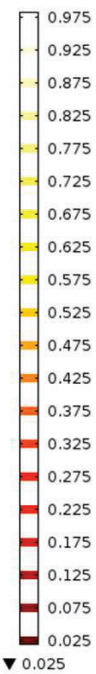

C

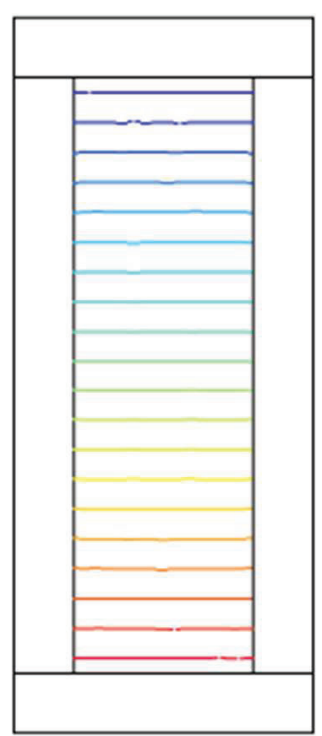

Table 3. Experimental and calculated using Maier model (from Equation (11)) and modified model with electron-ion forces against the experimental data

\begin{tabular}{lccccc}
\hline & \multicolumn{1}{c}{$\begin{array}{c}C_{1} \\
T_{\text {mean }} \\
\text { Alloy } \\
(\text { wt\%) }\end{array}$} & (K) & $\alpha_{\mathrm{T} \text { (exp) }}$ & $\alpha_{\mathrm{T} \text { (calculated) }}$ & $\begin{array}{c}\alpha_{\mathrm{T} \text { (modified) with }} \\
\text { electron-electron } \\
\text { forces }\end{array}$ \\
\hline Bi-Sn & 4.0 & 773 & $0.758 \pm 0.066$ & $0.785(3.6)$ & $0.8548(12.8)$ \\
Ag-Sn & 0.04 & 773 & $-0.175 \pm 0.049$ & $-0.162(-7.4)$ & $-0.191(9.1)$ \\
Co-Sn & 0.04 & 773 & $-1.86 \pm 0.040$ & $-1.712(-7.9)$ & $-1.686(-9.3)$ \\
Au-Sn & 0.07 & 823 & $0.837 \pm 0.012$ & $0.934(11.6)$ & $0.705(-15.8)$ \\
\hline
\end{tabular}

Errors are given in brackets.

heating case, the thermodiffusion causes the Sn component to migrate towards the cold bottom surface and therefore the $\mathrm{Bi}$ migrates to the top heated plate. Thus a linear separation occurs. Thermodiffusion factor is positive for $\mathrm{Sn}$, and a positive thermodiffusion factor causes the migration of Sn particles from

b

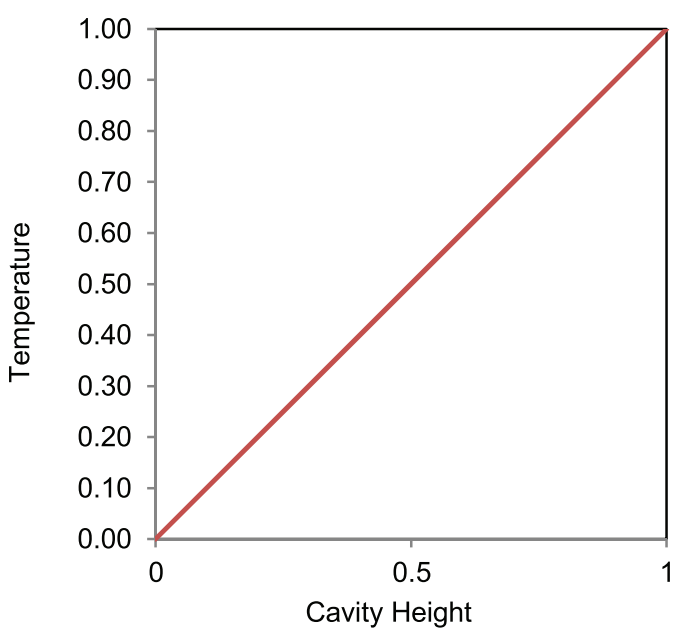

d

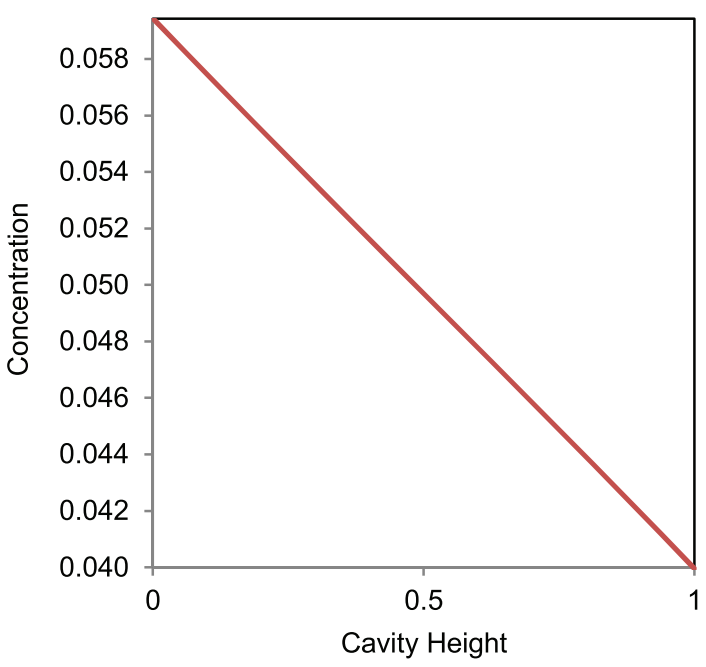

Figure 4. Temperature and concentration distribution with top heating condition; (a) lines of constant temperature; (b) temperature distribution along the cavity height; (c) lines of constant concentration; (d) concentration variation along the cavity height. 

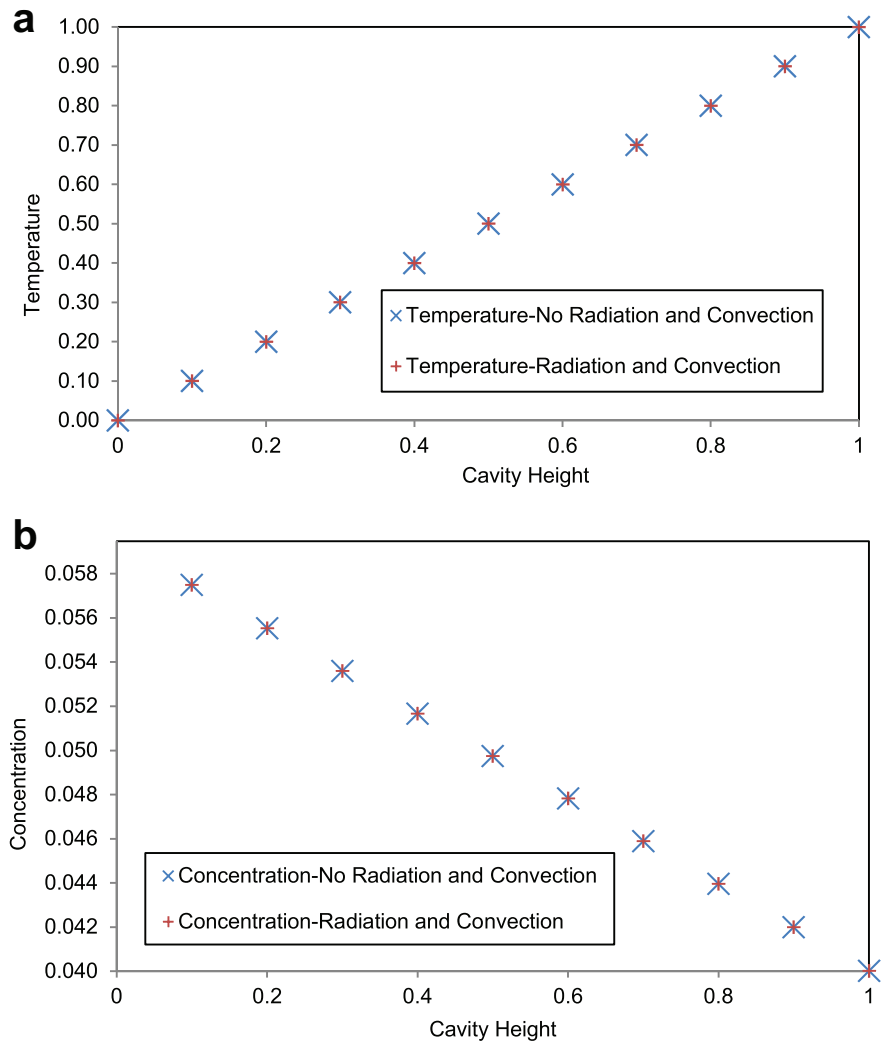

Figure 5. Comparison of (a) temperature distribution, and (b) concentration distribution by applying surface radiation and external natural convection on vertical walls to the ambient in Sn-Bi filled square cavity with thermodiffusion effect at $R a=1000$.

the hot zone to the cold zone. The pattern is displayed in Figure 4 depicting that the concentration increases by nearly $4 \%$ at the cold zone and decreases by the same amount near the hot zone. However, the concentration changes linearly as the function of the cavity's height. As for the case of temperature, the concentration distribution is linear with a constant gradient. These results for the variation of the temperature in a binary mixture resemble those of a single component fluid in the top heating configuration. Radiation and natural convection also did not affect the temperature and concentration profile.

Figure 5 shows the effect of natural convection from the outer surfaces of the sidewalls and radiation to the ambient on the temperature and concentration distribution. As these graphs indicate, in the range of temperatures considered here, the effect of natural convection and radiation are negligible.

\section{Case 2: Bottom heating condition}

In the case of bottom heating (Rayleigh-Benard configuration), the effect of the Rayleigh number at $R a=1000,2000, \ldots, 10000$ on the flow structure was studied. In this case, since the buoyancy force is present, once the flow becomes unstable the convective heat transfer becomes one of the major modes of heat and mass transfer in the cell. As the Ra number increases, the destabilising buoyancy force acting upward increases and outweighs the viscous forces and the thermodiffusion effect and thereby the flow becomes disturbed and unstable. This is due to the fact that the fluid particles tend to rise upward from the heated bottom surface due to the temperature gradient. The circulatory fluid motion in the cell manifests itself as a convective flow. In turn, this convective flow causes the temperature and concentration gradient to deviate from linearity. Figure $6 a$ and $b$ depicts temperature and concentration distribution and Figure 7 demonstrates the effect of the Ra number on the concentration distribution.

Figure 6a shows the temperature distribution for ten different Rayleigh numbers. It can be seen that at a $R a$ number of 1000 , the distribution is almost linear and as the $R a$ increases (2000 and higher), the nonlinearity becomes more noticeable. The isotherms show that the temperature rises from left to right. This is due to the fact that the flow is counter-clockwise in direction and the high temperature fluid molecules move upward closer to the right wall and the low temperature fluid molecules move downward closer to the left wall. Here, the thermodiffusion effects in addition to the buoyancy effect forces the $\mathrm{Sn}$ atoms/ions upward. In contrast, the gravity puts a downward force on Sn atoms, where the resultant forces generate a counter-clockwise flow. As Figure 6a indicates, the temperature variation increases with an increase in the $R a$ number giving rise to a more agitated counter-clockwise flow.

Figure $6 \mathrm{~b}$ shows the concentration distribution of $\mathrm{Sn}$ as the $R a$ number increases. It clearly demonstrates the fact that the concentration distribution closely follows the temperature distribution. In this case Sn atoms migrate from the bottom to the top and eventually because of positive thermodiffusion factor, the concentration of Sn atoms at the top zone increases as compared to the bottom zone. However the non-linearity of Sn distribution is due to the convective regime. Mixing starts to reduce the separation process. Figure 7 graphically shows the concentration distribution. The horizontal axis represents the height and vertical axis represents the concentration along the vertical direction. Figure 7 clearly demonstrates that as the $R a$ number increases, the concentration distribution asymptotically reaches the uniform distribution mainly at the centre of the cavity. From a pure diffusive regime to a convective regime, the concentration distribution of $\mathrm{Sn}$ changes from ea linear to a nonlinear distribution. The strong mixing at the centre of the cavity creates a constant Sn concentration with a large solute gradient near the hot and cold wall. Such a configuration is not suitable for a solidification process and should be avoided.

In the range of parameters studied here, our results showed that the effect of external natural convection and radiation are negligible and the temperature and concentration distribution do not vary significantly compared to the insulated wall condition. Also in the case of bottom heating, when the $R a$ number is large, the internal natural convection is dominant, convective flows are strong and thermodiffusion becomes less important, as the mixing of the species is prevailed.

\section{CONCLUSION}

In this research work, we proposed an expression to predict the thermodiffusion factor in a non-ideal binary molten metal alloy. The expression is based on the assumption that there are three forces acting on ions. These forces are due to thermal gradient, and induced concentrated gradient and induced electric field. The expression is in the framework of the linear non-equilibrium thermodynamics and needs only physical properties of the components, which are readily obtained. The proposed expression predicts experimentally measured the thermodiffusion factor rather accurately.

Furthermore, for the first time, numerical simulations were carried out in a binary molten metal alloy to study species segregation in the presence of the thermodiffusion effect coupled with surface radiation to the ambient as well as external natural 
a

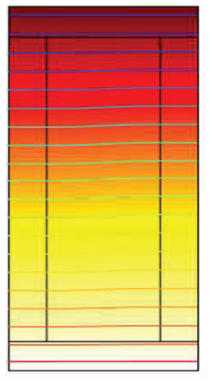

$\mathrm{Ra}=1000$

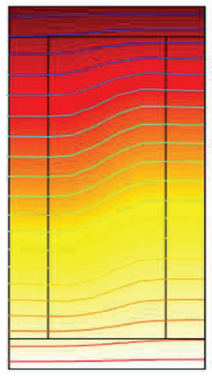

$\mathrm{Ra}=6000$

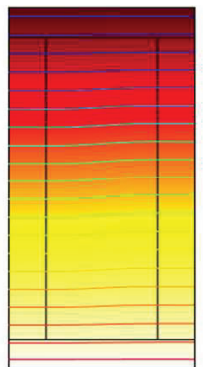

$\mathrm{Ra}=2000$

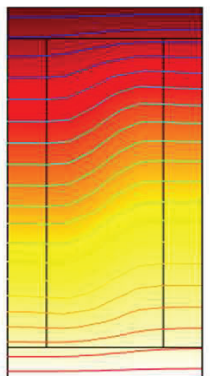

$\mathrm{Ra}=7000$

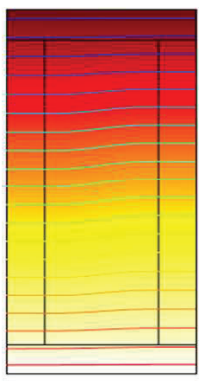

$\mathrm{Ra}=3000$

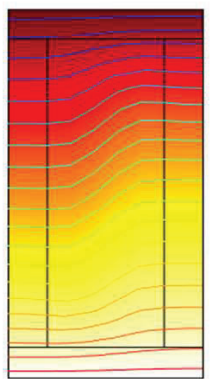

$\mathrm{Ra}=8000$

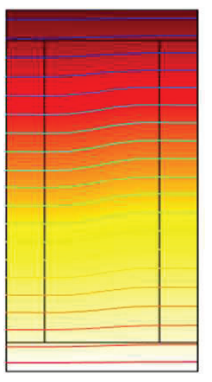

$\mathrm{Ra}=4000$

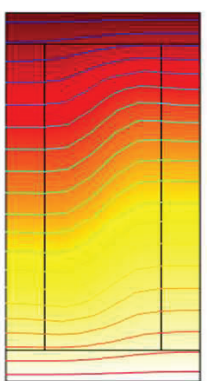

$\mathrm{Ra}=9000$

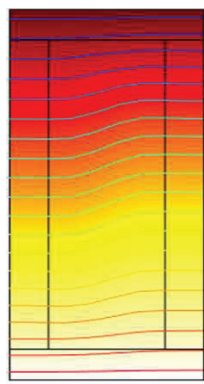

$\mathrm{Ra}=5000$

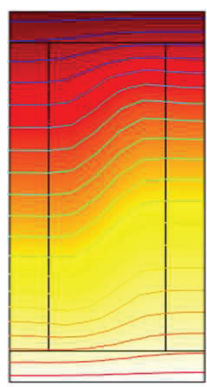

$\mathrm{Ra}=10000$ b

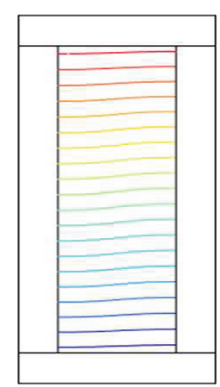

$\mathrm{Ra}=1000$

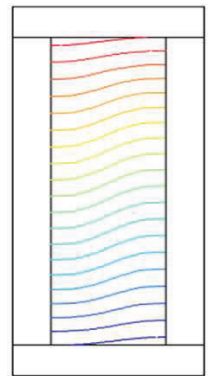

$\mathrm{Ra}=6000$

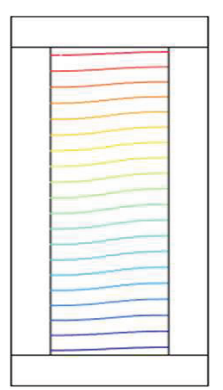

$\mathrm{Ra}=2000$

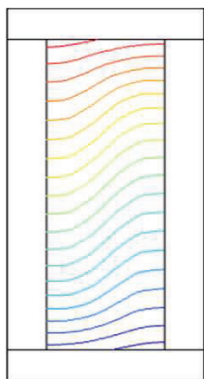

$\mathrm{Ra}=7000$

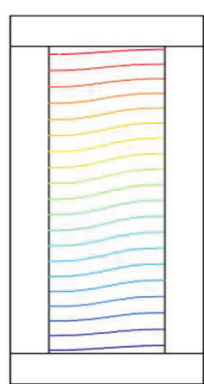

$\mathrm{Ra}=3000$

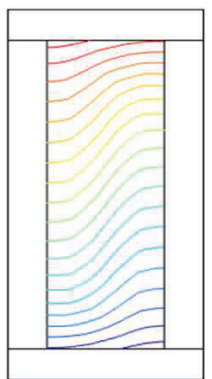

$\mathrm{Ra}=8000$

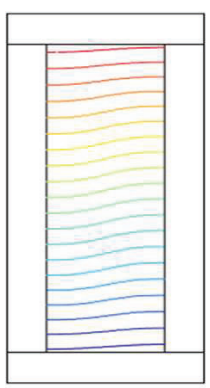

$\mathrm{Ra}=4000$

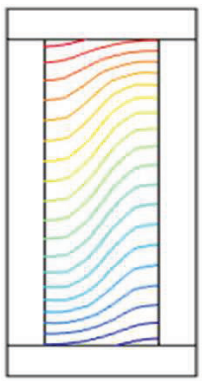

$\mathrm{Ra}=9000$

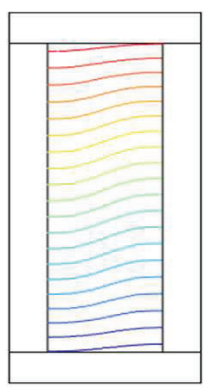

$\Delta 0.0597$

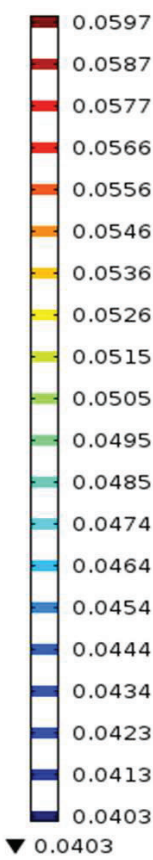

$\mathrm{Ra}=10000$

Figure 6. Temperature and concentration distribution in the cell in bottom heating; (a) constant temperature lines in the cavity; (b) constant concentration lines in the cavity.

convection. In the case of bottom heating, if the convection is strong (large $R a$ numbers), it is observed that the surface radiation to ambient, external natural convection and thermodiffusion have a small effect on the temperature and concentration distribution. However, for top heating, where convection is absent, thermodiffusion is the only effect that causes species segregation. It was also determined that similar to single phase fluids, in binary fluids, bottom heating promotes the convective flow that in turn causes the temperature and concentration to become dependent on the $R a$ number. In a $R a$ number between 1000 and 2000 convective flows start to develop in the cell. Because of the counter-clockwise direction of flow circulations, the temperature was typically higher 


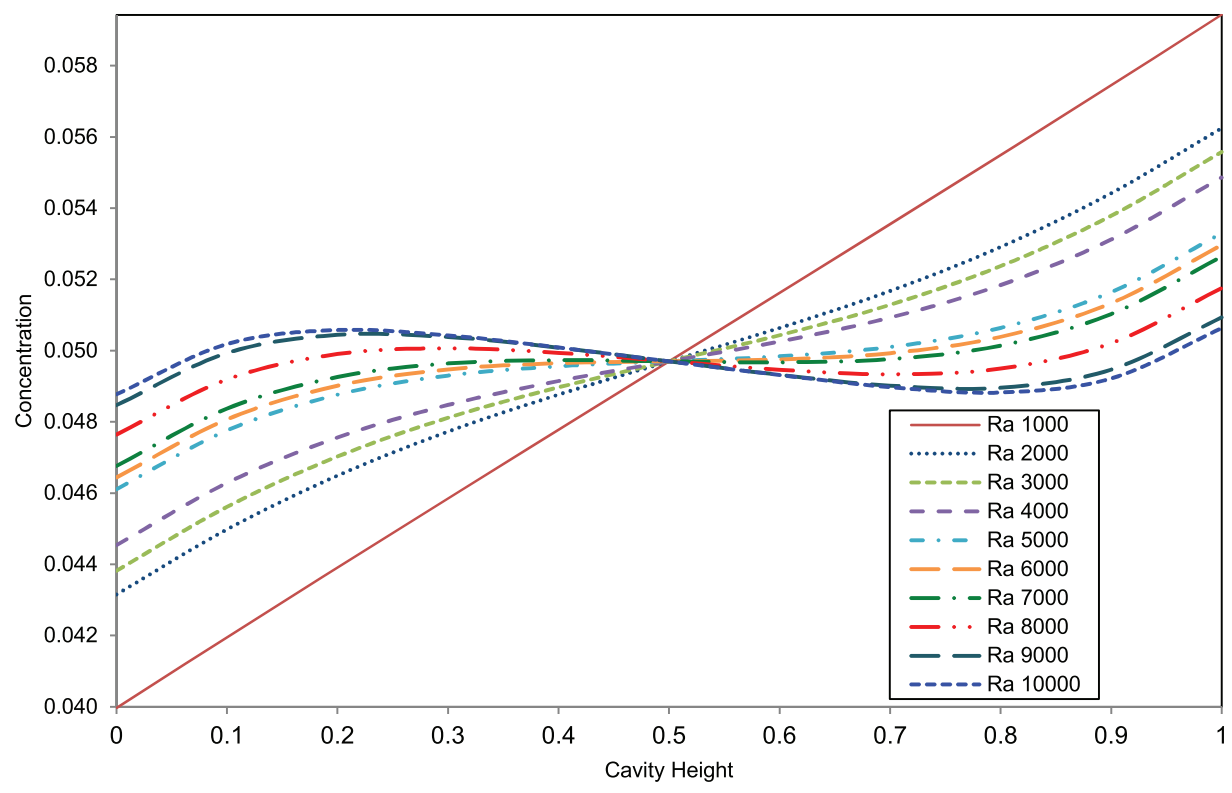

Figure 7. Variation of concentration at different Rayleigh numbers in bottom heating.

on the right-hand side of the cell, while the boundary conditions were the same on both sides.

Thermodiffusion was observed to play as a separating effect in binary mixtures in the top heating case, whereas in the bottom heat case, thermodiffusion is only effective in low $R a$ number conditions. In large $R a$ numbers, natural convection is present and dominant and thermodiffusion becomes a secondary effect.

\section{NOMENCLATURE}

$c_{j} \quad$ mass fraction of mixture component $j$

C non-dimensional concentration of a mixture component

$D \quad$ molecular diffusion coefficient $\left(\mathrm{cm}^{2} \mathrm{~s}^{-1}\right)$

$D_{\mathrm{T}} \quad$ thermodiffusion coefficient $\left(\mathrm{cm}^{2} \mathrm{~s}^{-1} \mathrm{~K}^{-1}\right)$

$E_{i}^{\mathrm{vis}} \quad$ activation energy of viscous flow of the component $i$ $\left(\mathrm{J} \mathrm{mol}^{-1}\right)$

g gravitational acceleration $\left(\mathrm{cm} \mathrm{s}^{-2}\right)$

$J_{i} \quad$ molar flux of component $i\left(\mathrm{~J} \mathrm{~cm}^{2} \mathrm{~mol}^{-1}\right)$

$L_{i k} \quad$ phenomenological coefficient

$p \quad$ pressure (Pa)

$P \quad$ non-dimensional pressure

$K \quad$ thermal conductivity $\left(\mathrm{J} \mathrm{s}^{-1} \mathrm{~cm}^{-1} \mathrm{~K}^{-1}\right)$

$C_{p} \quad$ specific heat capacity $\left(\mathrm{J} \mathrm{g}^{-1} \mathrm{~K}^{-1}\right)$

$Q_{k}^{*} \quad$ heat of transport of component $k\left(\mathrm{~J} \mathrm{~mol}^{-1} \mathrm{~K}^{-1}\right)$

$S_{T} \quad$ Soret coefficient $\frac{D T}{D}\left(K^{-1}\right)$

$T$ temperature (K)

$u \quad$ velocity component in the $x$-direction $\left(\mathrm{cm} \mathrm{s}^{-1}\right)$

$U$ non-dimensional velocity component in the $X$-direction $(-)$

$u_{\mathrm{o}} \quad$ characteristic velocity $=\sqrt{g \beta_{\mathrm{T}} \Delta T L}\left(\mathrm{~cm} \mathrm{~s}^{-1}\right)$

$v \quad$ velocity component in the $y$-direction $\left(\mathrm{cm} \mathrm{s}^{-1}\right)$

$V \quad$ non-dimensional velocity component in the $Y$-direction

$x_{i} \quad$ mole fraction of a mixture component $i$

$S_{\mathrm{ls}}(T) \quad$ partial specific entropy difference $\left(\mathrm{J} \mathrm{K}^{-1}\right)$

$S_{i}$

$|e| \quad$ absolute value of an electron

$Z_{i} \quad$ valence of ion $i$

$V_{i} \quad$ molar volume of component $i\left(\mathrm{~cm}^{3} \mathrm{~mol}^{-1}\right)$

$m_{i} \quad$ molar mass of component $i\left(\mathrm{~g} \mathrm{~mol}^{-1}\right)$

$\begin{array}{ll}R & \text { gas constant }\left(\mathrm{J} \mathrm{mol}^{-1} \mathrm{~K}^{-1}\right) \\ N & \text { Avogadro number } \\ K_{\mathrm{B}} & \text { Boltzman constant }\left(\mathrm{J} \mathrm{K}^{-1}\right) \\ E_{\mathrm{f}} & \text { Fermi energy }(\mathrm{eV})\end{array}$

Non-Dimensional Numbers

$\operatorname{Pr} \quad$ Prandtl number $=v / \alpha$

Re Reynolds number $=\rho_{0} u_{0} L / \mu$

Sc Schmidt number $=\mu / \rho D$

$R a \quad$ Rayleigh number $=(g \beta / v \alpha)\left(\Delta T L^{3}\right)$

\section{Greek Symbols}

$\alpha_{\mathrm{T}} \quad$ thermodiffusion factor $=T(D T / D)$

$\alpha \quad$ thermal diffusivity $\left(\mathrm{cm}^{2} \mathrm{~s}^{-1}\right)$

$\beta c \quad$ solutal expansion

$\beta_{\mathrm{T}} \quad$ thermal volume expansion $\left(\mathrm{K}^{-1}\right)$

$\theta \quad$ non-dimensional temperature $=T-T_{\mathrm{c}} / \Delta T$

$\mu_{k} \quad$ chemical potential of component $k\left(\mathrm{~J} \mathrm{~mol}^{-1}\right)$

$\eta \quad$ dynamic viscosity $\left(\mathrm{g} \mathrm{cm}^{-1} \mathrm{~s}^{-1}\right)$

$v \quad$ kinematic viscosity $\left(\mathrm{cm}^{2} \mathrm{~s}^{-1}\right)$

$\rho_{\mathrm{o}} \quad$ density of fluid at reference temperature $T_{\mathrm{o}}\left(\mathrm{g} \mathrm{cm}^{-3}\right)$

$\Delta c_{j} \quad$ concentration (mass fraction) difference of component $j(-)$

$\Delta T$ temperature difference $=T_{\mathrm{H}}-T_{\mathrm{C}}(\mathrm{K})$

$\nabla \quad$ spatial gradient of a variable

\section{Subscripts \\ C cold side of mixture \\ $\mathrm{H}$ hot side of mixture \\ o reference}

\section{ACKNOWLEDGEMENTS}

The authors acknowledge the financial support of the Natural Sciences and Engineering Research Council of Canada (NSERC). 


\section{REFERENCES}

[1] M. Eslamian, F. Sabzi, M. Z. Saghir, Phys. Chem. Chem. Phys. 2010, 12, 13835.

[2] S. Srinivasan, M. Z. Saghir, Appl. Math. Model. 2013, 37, 2850.

[3] W. Enge, W. Köhler, Phys. Chem. Chem. Phys. 2004, 6, 2373.

[4] R. Piazza, S. Iacopini, B. Triulzi, Phys. Chem. Chem. Phys. 2004, 6, 1616.

[5] J. Colombani, G. Gallie'ro, B. Duguay, J.-P. Caltagirone, F. Montel, P. A. Bopp, Phys. Chem. Chem. Phys. 2002, 4, 313.

[6] M. Eslamian, Front. Heat Mass Transf. 2011, 2, 043001.

[7] K. Ghorayeb, A. Firoozabadi, AIChE J. 2000, 46, 883.

[8] M. Eslamian, M. Z. Saghir, Can. J. Chem. Eng. 2012, 90, 936.

[9] M. Eslamian, C. G. Jiang, M. Z. Saghir, Philos. Mag. 2011, 92, 705.

[10] F. R. Winter, H. G. Drickamer, J. Phys. Chem. 1955, 59, 1229.

[11] M. Eslamian, M. Z. Saghir, Phys. Rev. E. 2009, 80, 011201.

[12] M. Eslamian, M. Z. Saghir, J. Non-Equilib. Thermodyn. 2009, 34, 97.

[13] M. Eslamian, M. Z. Saghir, Int. J. Therm. Sci. 2011, 50, 1232.

[14] R. M. Nogueira, M. A. Martinsb, F. Ampessanb, Therm. Eng. 2011, 4, 44.

[15] T. Basak, S. Roy, P. K. Sharma, I. Pop, Int. J. Heat Mass Transf. 2009, 52, 2224.

[16] S. Roy, T. Basak, Int. J. Eng. Sci. 2005, 43, 668.

[17] T. Basak, S. Roy, P. K. Sharma, I. Pop, Int. J. Therm. Sci. 2009, $48,891$.

[18] M. Ouriemi, P. Vasseur, A. Bahloul, L. Robillard, Int. J. Therm. Sci. 2006, 45, 752.

[19] M. Paroncini, F. Corvaro, Int. J. Therm. Sci. 2008, 48, 1683.

[20] Y. Kawaguchi, H. Yasuda, Y. Okano, S. Dost, Int. J. Transp. Phenomena 2005, 7, 175.

[21] Y. Okano, H. Kondo, S. Dost, J. Crystal Growth 2002, 237, 1769.

[22] P. Barvinschi, F. Barvinschi, Coupled Heat Transfer and Fluid Dynamics Modeling of InSb Solidification. AIP Conference Proceeding, 2011, 190.

[23] M. Shemirani, Z. Saghir, Numerical Modeling Study on the Effects of Both Radial and Axial Temperature Gradient on a Large Diameter Si0.25Ge0.75 Alloy in a Bridgman Setting, 2012, May 29-June 1, Istanbul, Turkey.

[24] M. Vynnycky, S. Kimura, Int. J. Heat Mass Transf. 2007, 50, 5204.

[25] F. Mechighel, S. Dost, B. Pateyron, M. El Ganaoui, M. Kadja, Modeling of Silicon Transport into Germanium Using a Simplified Crystal Growth Technique, COMSOL Proceeding Conference, 2009, Milan.

[26] D. Celentano, M. Cruchaga, N. Moraga, J. Fuentes, Numerical Heat Transf. 2001, Part A 39, 631.

[27] M. A. Rady, A. K. Mohanty, Numerical Heat Transf. 1996, Part A 29, 49.

[28] C. Balaji, S. P. Venkateshan, Int. J. Heat Fluid Flow 1993, 14, 260.

[29] C. Balaji, S. P. Venkateshan, Int. J. Heat Fluid Flow 1994, 15, 249.
[30] M. Akiyama, Q. P. Chong, Numerical Heat Transf. 1997, 31, 419.

[31] N. Ramesh, C. Balaji, S. P. Venkateshan, Int. J. Transp. Phenomena 1999, 1, 205.

[32] N. Ramesh, S. P. Venkateshan, J. Thermophys. Heat Transf. 1999, 13, 299.

[33] E. H. Ridouane, M. Hasnaoui, A. Amahmid, A. Raji, Numerical Heat Transf. Fluid Flow 2004, 45, 289.

[34] C. Gururaja Rao, A. Venkata Krishna, P. Naga Srinivas, Numerical Heat Transf. Fluid Flow 2005, 48, 427.

[35] A. Bahlaoui, A. Raji, M. Hasnaoui, Int. J. Numerical Methods Heat Fluid Flow 2006, 16, 431.

[36] C. Y. Han, S. W. Baek, Numerical Heat Transf. Fluid Flow 2000, 37, 249.

[37] C. Balaji, S. P. Venkateshan, Int. J. Heat Fluid Flow 1994, 15, 317.

[38] C. Balaji, S. P. Venkateshan, Int. J. Heat Fluid Flow 1995, 14, 260.

[39] J. F. Hinojosa, C. A. Estrada, R. E. Cabanillas, G. Alvarez, Numerical Heat Transf. Fluid Flow 2005, 48, 179.

[40] A. A. Dehghan, M. Behnia, Trans. ASME 1996, 118, 56.

[41] J. L. Lage, A. Bejan, Int. J. Heat Mass Transf. 1993, 36, 2027.

[42] E. K. Lakhal, M. Hasnaoui, P. Vasseur, E. Bilgen, Numerical Heat Transf. Fluid Flow 1995, 27, 319.

[43] E. K. Lakhal, M. Hasnaoui, P. Vasseur, Int. J. Heat Mass Transf. 1999, 42, 3927.

[44] B. V. Antohe, J. L. Lage, Int. J. Heat Mass Transf. 1996, 39, 1121.

[45] B. V. Antohe, J. L. Lage, Int. J. Heat Mass Transf. 1997, 40, 1313.

[46] H. S. Kwak, J. M. Hyun, J. Fluid Mech. 1996, 329, 65.

[47] H. S. Kwak, K. Kuwahara, J. M. Hyun, Int. J. Heat Mass Transf. 1998, 41, 2837.

[48] B. Abourida, M. Hasnaoui, S. Douamna, Numerical Heat Transf. A 1999, 36, 737.

[49] D. Maier, D. Klimm, R. Fornari, J. Chem. Phys. Lett. 2007, 444, 202

[50] M. Gerl, J. Phys. Chem. Solids 1967, 28, 725.

[51] T. E. Faber, An Introduction to the Theory of Liquid Metals, Cambridge University Press, London 1972.

[52] S. Van Vaerenbergh, J. P. Garandet, J. P. Praizey, J. C. Legros, Phys. Rev. E 1998, 58, 1866.

[53] P. Praizey, Int. J. Heat Mass Transf. 1989, 32, 2385.

[54] COMSOL Multiphysics Software, 2012 (4.3a).

[55] R. Haase, Thermodynamics of Irreversible Processes, 1st edition, Addison-Wesley, 1969, 321.

[56] L. J. T. M. Kempers, J. Chem. Phys. 2001, 115, 6330.

[57] K. Shukla, A. Firoozabadi, Ind. Eng. Chem. Res. 1998, 37, 3331.

Manuscript received July 5, 2013; revised manuscript received September 2, 2013; accepted for publication September 12, 2013. 